\title{
Neonatal Pneumothorax Pressures Surpass Higher Threshold in Lung Recruitment Maneuvers: An In Vivo Interventional Study
}

\author{
Patricio González-Pizarro MD, Javier García-Fernández MD PhD, Susana Canfrán DVM PhD, and \\ Fernando Gilsanz MD PhD
}

\begin{abstract}
BACKGROUND: Causing pneumothorax is one of the main concerns of lung recruitment maneuvers in pediatric patients, especially newborns. Therefore, these maneuvers are not performed routinely during anesthesia. Our objective was to determine the pressures that cause pneumothorax in healthy newborns by a prospective experimental study of 10 newborn piglets ( $<48 \mathrm{~h}$ old) with healthy lungs under general anesthesia. METHODS: The primary outcome was peak inspiratory pressure (PIP) causing pneumothorax. Animals under anesthesia and bilateral chest tube catheterization were randomly allocated to 2 groups: one with PEEP and fixed inspiratory driving pressure of $15 \mathrm{~cm} \mathrm{H}_{2} \mathrm{O}$ (PEEP group) and the second one with PEEP $=0 \mathrm{~cm} \mathrm{H}_{2} \mathrm{O}$ and non-fixed inspiratory driving pressure (zero PEEP group). In both groups, the ventilation mode was pressurecontrolled, and PIP was raised at 2-min intervals, with steps of $5 \mathrm{~cm} \mathrm{H} \mathrm{H}_{2} \mathrm{O}$ until air leak was observed through the chest tubes. The PEEP group raised PIP through 5-cm $\mathrm{H}_{2} \mathrm{O}$ PEEP increments, and the zero PEEP group raised PIP through 5-cm $\mathrm{H}_{2} \mathrm{O}$ inspiratory driving pressure increments. RESULTS: Pneumothorax was observed with a PIP of $90.5 \pm 15.7 \mathrm{~cm} \mathrm{H}_{2} \mathrm{O}$ with no statistically significant differences between the PEEP group $\left(92 \pm 14.8 \mathrm{~cm} \mathrm{H}_{2} \mathrm{O}\right)$ and the zero PEEP group $\left(89 \pm 18.2 \mathrm{~cm} \mathrm{H}_{2} \mathrm{O}\right)$. The zero PEEP group had hypotension, with a PIP of $35 \mathrm{~cm} \mathrm{H}_{2} \mathrm{O}$; the PEEP group had hypotension, with a PIP of $60 \mathrm{~cm} \mathrm{H}_{2} \mathrm{O}(P=.01)$. The zero PEEP group presented bradycardia, with PIP of $40 \mathrm{~cm} \mathrm{H}_{2} \mathrm{O}$; the PEEP group presented bradycardia, with PIP of $70 \mathrm{~cm} \mathrm{H}_{2} \mathrm{O}$ $(P=.002)$. CONCLUSIONS: Performing recruitment maneuvers in newborns without lung disease is a safe procedure in terms of pneumothorax. Pneumothorax does not seem to occur in the clinically relevant PIPs of $<50 \mathrm{~cm} \mathrm{H}_{2} \mathrm{O}$. Hemodynamic impairment may occur with high driving pressures. More studies are needed to determine the exact hemodynamic impact of these procedures and pneumothorax PIP in poorly compliant lungs. Key words: barotrauma, mechanical ventilation; pediatrics; ventilator-induced lung injury; positive-pressure respiration; anesthesia [Respir Care 2016;61(2):142-148. ㅇ 2016 Daedalus Enterprises]
\end{abstract}

\section{Introduction}

Lung collapse invariably occurs during mechanical ventilation and commonly after induction of general anesthe-

Dr González-Pizarro is affiliated with the Anaesthesia and Intensive Care Department, Akademiska Sjukhuset, Uppsala, Sweden. Dr GarcíaFernández is affilated with the Anaesthesiology and Critical Care Department, Puerta de Hierro University Hospital, Madrid, Spain. Dr Canfrán is affiliated with the Veterinary Clinical Hospital, Complutense University, Madrid, Spain. Dr Gilsanz is affiliated with the Anaesthesiology Department, La Paz University Hospital, Madrid, Spain.

This work was supported by the Department of Anaesthesiology, La Paz University Hospital, Madrid, Spain. The authors have disclosed no conflicts of interest. sia. ${ }^{1,2}$ The use of recruitment maneuvers has been proposed as a useful technique to reverse atelectasis during general anesthesia. ${ }^{3-6}$ Nevertheless, there is no standard,

\footnotetext{
Drs González-Pizarro and García-Fernández presented preliminary data for this study as a poster at the European Society of Anaesthesiology (ESA) Euroanaesthesia meeting, held May 31 to June 3, 2014, in Stockholm, Sweden.

Correspondence: Patricio González-Pizarro MD, Akademiska Sjukhuset, Anesthesia and Intensive Care Department, Uppsala, 75185 Sweden. E-mail: pgpizarro@gmail.com.
}

DOI: $10.4187 /$ respcare. 04250 
universally accepted method of performing recruitment maneuvers.

There are many clinical trials described in the literature where different types of recruitment maneuvers have been used in trying to reopen collapsed lung regions, and discussion has focused on the minimum level of PEEP required to keep them open. Our goal was to determine the range of peak inspiratory pressures (PIPs) producing pneumothorax and compare it with the PIP range commonly used in recruitment maneuvers of healthy newborns in the operating theater setting.

\section{See the Related Editorial on Page 260}

One way of performing a recruitment maneuver was described by Tusman ${ }^{7}$ and is based on the slow increase of the inspiratory pressure with PEEP using step increments and a fixed inspiratory driving pressure (PIP - PEEP) to fully reopen collapsed lung regions, followed by a decremental PEEP titration in order to set the ideal open-lung PEEP that maintains the recruited lungs open. The aim of such a strategy is to prevent ventilator-induced lung injury by reversing lung collapse and hence avoiding cyclic tidal recruitment and to minimize lung overdistention by limiting the inspiratory driving pressure above the set openlung PEEP. ${ }^{7-11}$ These slow stepwise increments in PIP, keeping inspiratory driving pressure $<15 \mathrm{~cm} \mathrm{H}_{2} \mathrm{O}$, have less hemodynamic impact, particularly in children, and help to set the optimal PEEP. Other types of recruitment maneuvers frequently used in the operating theater are CPAP of $40 \mathrm{~cm} \mathrm{H}_{2} \mathrm{O}$ for 8-40 $\mathrm{s}$ or a few breaths at a high rate and high pressure ( $\mathrm{PIP}=50 \mathrm{~cm} \mathrm{H}_{2} \mathrm{O} / \mathrm{PEEP}=5 \mathrm{~cm} \mathrm{H}_{2} \mathrm{O}$ ).

Nevertheless, the recruitment maneuver has not yet gained widespread acceptance in routine pediatric mechanical ventilation. One of the main reasons is that there are concerns regarding the risks associated with recruitment maneuvers, including minor hemodynamic impairment, ${ }^{12,13}$ barotrauma, ${ }^{14,15}$ and tissue damage of the lung and distal organs. ${ }^{16,17}$ Barotrauma is one of the major clinical concerns, especially in neonates and infants, due to their infinite thorax compliance, which makes them particularly sensitive to increases in airway pressure and prone to pneumothorax. ${ }^{18,19}$ Most studies regarding recruitment maneuvers have been conducted in adult lungs with ARDS, 1,10,11,20 and information regarding the response to recruitment maneuvers in either healthy or sick pediatric patients is scarce.

The lungs of healthy neonates and infants easily collapse after induction of anesthesia because their functional residual capacity is always below the airway closing volume. ${ }^{21}$ Therefore, the development of atelectasis during general anesthesia is a constant finding. ${ }^{5}$ There are reasons to believe that the pressures needed to recruit the lungs and the safety of recruitment maneuvers may differ in young healthy lungs compared with adult diseased lungs. If rou-

\section{QUICK LOOK}

\section{Current knowledge}

Recruitment maneuvers are frequently employed to reverse atelectasis and improve gas exchange in mechanically ventilated patients. Elevated pressures are commonly associated with hemodynamic embarrassment and less commonly with air leaks or barotrauma. Complications of recruitment maneuvers might occur.

\section{What this paper contributes to our knowledge}

In a neonatal piglet model with normal lung mechanics, pressures resulting in pneumothorax following a recruitment maneuver were greater than those typically used clinically. Hemodynamic impairment was commonly seen, with animals at zero PEEP having greater impairment that those at higher PEEP. Limiting driving pressure during recruitment can reduce hemodynamic compromise.

tine recruitment maneuvers are to be implemented in pediatric patients, their safety and efficacy must be explored in more detail. Therefore, it is relevant to determine the pressure range causing pneumothorax.

The aim of this study is to determine the PIPs causing pneumothorax in an experimental model using healthy newborn piglets. The hypothesis of the experiment is that recruitment maneuvers involving increasing PIP without increasing PEEP induce a greater degree of barotrauma and risk of pneumothorax as compared with maneuvers that maintain a constant $\delta$-pressure (PIP - PEEP). Therefore, we want to determine as well whether there is any difference in the pneumothorax PIP using a ventilation strategy with constant (PEEP group) or increasing inspiratory driving pressure (zero PEEP group).

We compared 2 different ventilation strategies producing pneumothorax: one with a fixed inspiratory driving pressure of $15 \mathrm{~cm} \mathrm{H}_{2} \mathrm{O}$ and PIP raised upon PEEP increments (PEEP group) and one with zero PEEP (PEEP $=0 \mathrm{~cm} \mathrm{H}_{2} \mathrm{O}$ ) and PIP raised directly, thus having a non-fixed inspiratory driving pressure on every breath cycle and risking the production of cyclic overdistention and cyclic tidal recruitment (zero PEEP group). It is not the purpose of this study to determine the optimum PEEP after a recruitment maneuver but rather to help the clinician set a range of PIPs at which pneumothorax is likely to happen.

\section{Methods}

\section{Ethics}

The study was approved by the ethical committee for experimental research of La Paz University Hospital (Eth- 
Table 1. Peak Inspiratory Pressure Resulting in Pneumothorax According to Group After Randomization

\begin{tabular}{llc}
\hline \hline Animal & Group & $\begin{array}{c}\text { Pneumothorax Peak Inspiratory } \\
\text { Pressure, } \mathrm{cm} \mathrm{H}_{2} \mathrm{O}\end{array}$ \\
\hline 1 & PEEP & 70 \\
2 & Zero PEEP & 65 \\
3 & PEEP & 105 \\
4 & PEEP & 95 \\
5 & Zero PEEP & 85 \\
6 & Zero PEEP & 85 \\
7 & Zero PEEP & 115 \\
8 & Zero PEEP & 95 \\
9 & PEEP & 105 \\
10 & PEEP & 85 \\
\hline
\end{tabular}

ical Committee N9 32-2011) (Madrid, Spain) on November 10, 2011. The study was conducted in accordance with ARRIVE (Animals in Research: In Vivo Experiments) standards. In addition, the prospective research was undertaken in conformity with the national and institutional guidelines for the care and use of experimental animals (RD1201/2005).

\section{Animals}

Ten newborn piglets $(<48 \mathrm{~h}$ old $)$ of the LandraceLarge White breed with an average weight of $3.2 \pm 0.4$ $\mathrm{kg}$ were selected. The estimation of the sample size was conducted taking similar studies as a reference. ${ }^{22,23}$ All animals studied had been declared healthy after a veterinary examination.

Animals were sedated with ketamine $\left(10 \mathrm{mg} \mathrm{kg}^{-1}\right.$ intramuscularly), diazepam ( $0.3 \mathrm{mg} \mathrm{kg}^{-1}$ intramuscularly), and atropine $\left(0.01 \mathrm{mg} \mathrm{kg}^{-1}\right.$ intramuscularly) $20 \mathrm{~min}$ before anesthesia induction with sevoflurane (6\% inhaled), fentanyl (1.5 $\mu \mathrm{g} \mathrm{kg}^{-1}$ intravenously), and cisatracurium (0.5 mg kg ${ }^{-1}$ intravenously). Anesthesia was maintained with $1.5 \%$ sevoflurane and a fentanyl infusion $\left(1 \mu \mathrm{g} \mathrm{kg}^{-1}\right.$ $\left.\mathrm{h}^{-1}\right)$.

\section{Preparation}

Piglets were intubated with a 3.5-mm internal diameter cuffed endotracheal tube and ventilated (Flow i C30, MAQUET, Rastatt, Germany) in pressure-controlled mode according to a randomization protocol (Table 1). Monitoring (Omicron Altea Monitor, RGB Medical Devices, Madrid, Spain) consisted of electrocardiography (lead II), pulse oximetry, invasive blood pressure with carotid surgical dissection, and temperature.

Bilateral chest tubes (10 French, Kendall Argyle, Covidien, Dublin, Ireland) were inserted in a mid-anterior line at the level of the front limbs. Careful surgical dissection

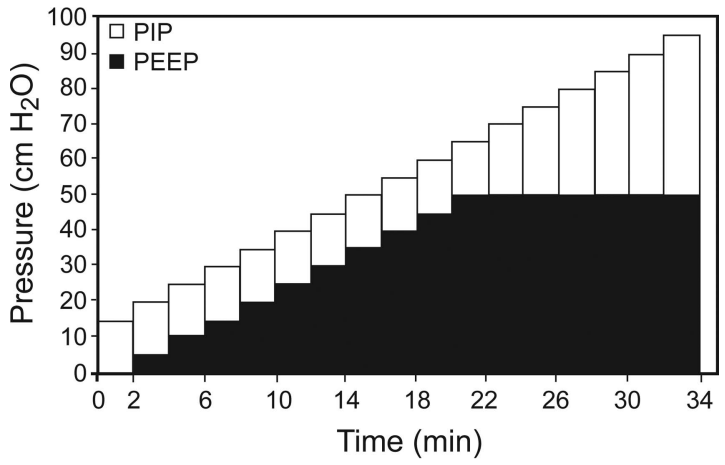

Fig. 1. Ventilation protocol. The PEEP group raised peak inspiratory pressure (PIP) through $5-\mathrm{cm} \mathrm{H}_{2} \mathrm{O}$ PEEP increments every 2 min while keeping a fixed inspiratory driving pressure of $15 \mathrm{~cm} \mathrm{H}_{2} \mathrm{O}$. There is no current anesthesia workstation available supporting PEEP levels $>50 \mathrm{~cm} \mathrm{H}_{2} \mathrm{O}$; therefore, breaking the fixed inspiratory driving pressure was necessary in those animals that already had reached PEEP of $50 \mathrm{~cm} \mathrm{H} \mathrm{H}_{2} \mathrm{O}$ without signs of pneumothorax. In those cases, PIP was increased directly while keeping PEEP constant at $50 \mathrm{~cm} \mathrm{H}_{2} \mathrm{O}$.

was performed, and before the insertion of each chest tube, animals were disconnected from ventilation to ease lung collapse and avoid any possible risk of iatrogenic lung damage. Then each chest tube was carefully sutured to the skin to prevent leakages and connected to water traps. Tubes were covered by $1 \mathrm{~cm} \mathrm{H}_{2} \mathrm{O}$ at their distal end in the water traps.

\section{Ventilation Protocol}

All animals were ventilated for $1 \mathrm{~h}$ before the experiment to allow atelectasis to occur with these same settings (pressure-controlled ventilation, $\mathrm{PIP}=15 \mathrm{~cm} \mathrm{H}_{2} \mathrm{O}$, zero PEEP, 25 beats/min, I-E ratio $1: 1, \mathrm{~F}_{\mathrm{IO}_{2}} 60 \%, 1.0 \mathrm{~L} / \mathrm{min}$ fresh gas flow, and end-tidal sevoflurane concentration of $1.5 \%$ in an air/oxygen mix). They were then randomly allocated to 2 groups. The first group (PEEP group) had a constant driving pressure of $15 \mathrm{~cm} \mathrm{H}_{2} \mathrm{O}$, and PIP was raised in 5-cm $\mathrm{H}_{2} \mathrm{O}$ PEEP increments every 2 min, starting from zero PEEP, until 50-cm $\mathrm{H}_{2} \mathrm{O}$ PEEP was reached. If no air leak was noticed, it was necessary to break the fixed $\delta$-pressure to keep raising the PIP, since no anesthesia workstations in the market support PEEP levels $>50 \mathrm{~cm} \mathrm{H}_{2} \mathrm{O}$. From that point on, every step continued with $5-\mathrm{cm} \mathrm{H}_{2} \mathrm{O}$ PIP increments (Fig. 1).

The second group (zero PEEP group) kept zero PEEP during the whole experiment, and PIP was raised in 5-cm $\mathrm{H}_{2} \mathrm{O}$ increments every 2 min (Fig. 2), until bubbling was noticed in the water traps. Each single experiment lasted for a different time, until pneumothorax was witnessed in the form of a continuous air leak in the PEEP group or inspiratory air leak in the zero PEEP group. 


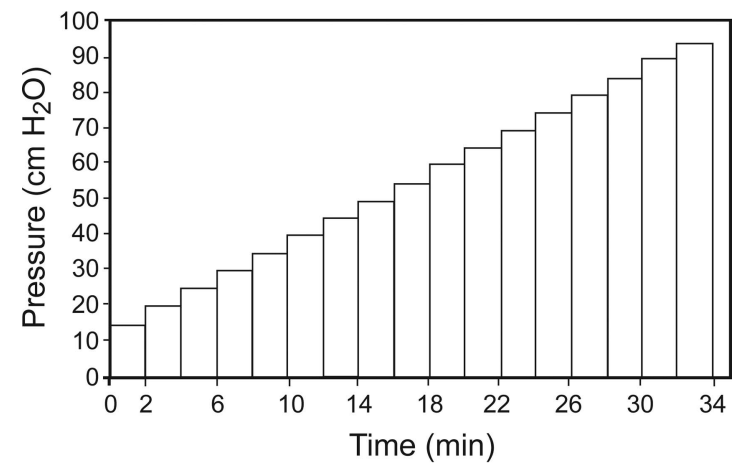

Fig. 2. Zero PEEP ventilation protocol. The zero PEEP group raised PIP directly in 5- $\mathrm{cm} \mathrm{H}_{2} \mathrm{O}$ increments every 2 min while keeping zero PEEP during the entire experiment.

Table 2. Pneumothorax Peak Inspiratory Pressure Values According to Each Ventilation Group

\begin{tabular}{lccc}
\hline \hline $\begin{array}{c}\text { Peak Inspiratory } \\
\text { Pressure }\end{array}$ & $\begin{array}{c}\text { PEEP } \\
(n=5)\end{array}$ & $\begin{array}{c}\text { Zero PEEP } \\
(n=5)\end{array}$ & $\begin{array}{c}\text { All } \\
(N=10)\end{array}$ \\
\hline Mean $\pm \mathrm{SD}, \mathrm{cm} \mathrm{H} \mathrm{H}_{2} \mathrm{O}$ & $92 \pm 14.8$ & $89 \pm 18.2$ & $90.5 \pm 15.7$ \\
Median, cm $\mathrm{H}_{2} \mathrm{O}$ & 95 & 85 & 90 \\
Maximum, $\mathrm{cm} \mathrm{H}_{2} \mathrm{O}$ & 105 & 115 & 115 \\
Minimum, cm $\mathrm{H}_{2} \mathrm{O}$ & 70 & 65 & 65 \\
\hline
\end{tabular}

Hemodynamic monitoring started after the first hour of ventilation with PIP of $15 \mathrm{~cm} \mathrm{H}_{2} \mathrm{O}$ and zero PEEP.

\section{Statistical Analysis}

Data are expressed as mean \pm SD for parametric data and median (range) for non-parametric data. We used the Student $t$ test for independent data as a parametric test and the Mann-Whitney U-test as a non-parametric test to compare both groups. All statistical tests were considered bilateral, and $P<.05$ was considered statistically significant. The statistical analysis was performed using SAS 9.1 (SAS Institute, Cary, North Carolina).

\section{Results}

\section{Pneumothorax Pressures}

Peak inspiratory pressure causing pneumothorax for all studied animals was $90.5 \pm 15.7 \mathrm{~cm} \mathrm{H}_{2} \mathrm{O}$. We found no significant difference $(P=.78)$ between the 2 groups. The PEEP group reached a PIP of $92 \pm 14.8 \mathrm{~cm} \mathrm{H}_{2} \mathrm{O}$, and the zero PEEP group reached a PIP of $89 \pm 18.2 \mathrm{~cm} \mathrm{H}_{2} \mathrm{O}$. The highest PIP recorded causing pneumothorax was $115 \mathrm{~cm} \mathrm{H}_{2} \mathrm{O}$, and the lowest was $65 \mathrm{~cm} \mathrm{H}_{2} \mathrm{O}$. Results are shown in Tables 1 and 2.
Table 3. Peak Inspiratory Pressures (mean \pm SD) in $\mathrm{cm}_{2} \mathrm{O}$ Corresponding to a 20\% Decrease From Baseline for Each Hemodynamic Value

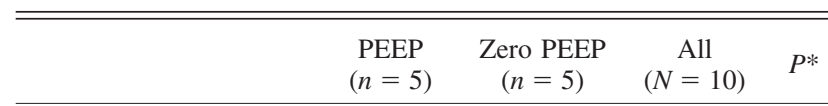

$\begin{array}{lllll}\text { Systolic arterial pressure } & 62.5 \pm 16.6 & 37.5 \pm 8.7 & 50.0 \pm 18.1 & .037\end{array}$ $\begin{array}{lllll}\text { Diastolic arterial pressure } 63.8 \pm 14.4 & 37.5 \pm 6.5 & 50.6 \pm 17.4 & .02\end{array}$ $\begin{array}{lllll}\text { Mean arterial pressure } & 63.8 \pm 14.4 & 33.8 \pm 7.5 & 48.8 \pm 19.2 & .01\end{array}$ Pulse $72.5 \pm 6.5 \quad 41.3 \pm 10.3 \quad 56.9 \pm 18.5 \quad .002$

* $P$ values refer to a $t$ test between the PEEP and zero PEEP group means.

\section{Hemodynamic Impact}

The PEEP group had a higher PIP (mean PIP = $62.5 \mathrm{~cm} \mathrm{H}_{2} \mathrm{O}$ ) at which a $20 \%$ decrease in mean arterial pressure from baseline was noted in comparison with the zero PEEP group (mean PIP $\left.=37.5 \mathrm{~cm} \mathrm{H}_{2} \mathrm{O}\right)(P=.01$ ). Similar results were found for systolic blood pressure and diastolic blood pressure (Table 3).

Regarding heart rate, the zero PEEP group presented a $20 \%$ decrease from baseline with a mean PIP of $42.5 \mathrm{~cm} \mathrm{H}_{2} \mathrm{O}$, whereas the PEEP group showed a pulse decreased by $20 \%$ from baseline with mean PIP of $72.5 \mathrm{~cm} \mathrm{H}_{2} \mathrm{O}$. These differences were highly significant $(P=.002)$. Results are summarized in Table 3 .

We found no significant $(P=.058)$ difference in highest pulse values during the experiment between the zero PEEP group (highest heart rate value corresponds to a PIP of $22.5 \pm 2.9 \mathrm{~cm} \mathrm{H}_{2} \mathrm{O}$ ) and the PEEP group (PIP of $43.8 \pm 18.0 \mathrm{~cm} \mathrm{H}_{2} \mathrm{O}$ ), whereas there was a statistically significant difference $(P=.03)$ for highest mean arterial pressure values (PEEP group, PIP $40.0 \pm 14.7 \mathrm{~cm} \mathrm{H}_{2} \mathrm{O}$; zero PEEP group, PIP $18.8 \pm 4.8 \mathrm{~cm} \mathrm{H}_{2} \mathrm{O}$ ) achieved in the experiment.

\section{Mortality Analysis}

PIP producing asystole in the PEEP group was $73.8 \pm 4.8 \mathrm{~cm} \mathrm{H}_{2} \mathrm{O}$, whereas the zero PEEP group pressures for the same result reached $77.5 \pm 18.5 \mathrm{~cm} \mathrm{H}_{2} \mathrm{O}$. No significant difference was found between the 2 groups. Figure 3 shows a box plot comparison regarding PIPs causing bradycardia, hypotension, asystole, and pneumothorax.

\section{Discussion}

Data describing precise pneumothorax pressures either in adults or in children are very scarce. In the current study, the only relevant factor that determines pneumothorax is the PIP. No difference was observed between the 2 


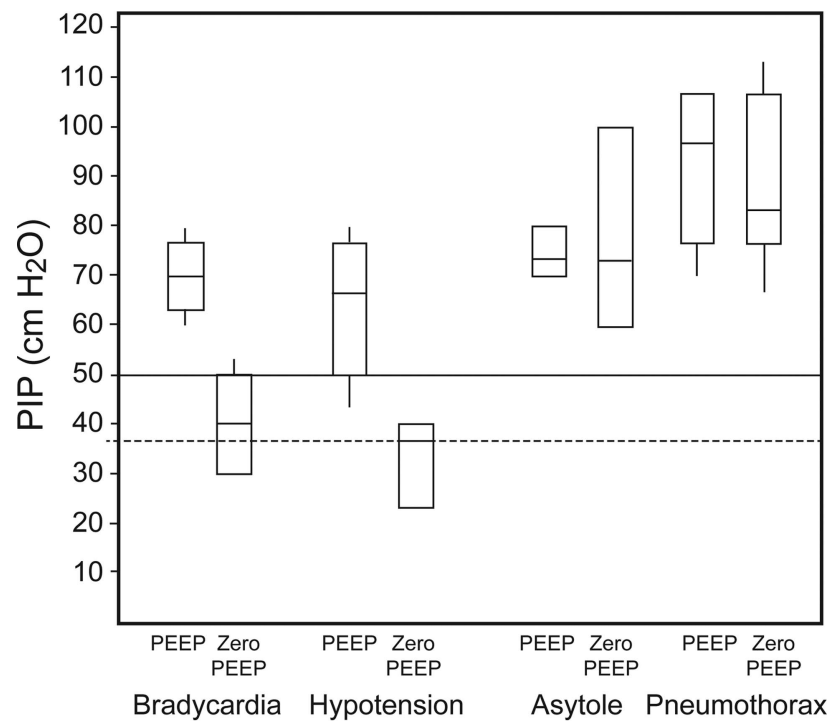

Fig. 3. Box plots comparing peak inspiratory pressures (PIP) causing the 4 main experimental outcomes: bradycardia, hypotension, asystole, and pneumothorax. Both PEEP and zero PEEP groups are compared for each outcome. Bradycardia and hypotension are defined by a $20 \%$ decrease from baseline. The dashed line denotes the $35-\mathrm{cm} \mathrm{H}_{2} \mathrm{O}$ threshold, and the solid line shows the $50-\mathrm{cm} \mathrm{H}_{2} \mathrm{O}$ threshold. All animals in the zero PEEP group presented bradycardia significantly earlier $(P=.002)$ than those in the PEEP group, the former even at the range of clinically relevant pressures. The zero PEEP group also presented hypotension sooner than the PEEP strategy $(P=.01)$. Finally, all animals during the experiment suffered asystole before pneumothorax. These 2 last outcomes happened considerably above the higher peak inspiratory pressure threshold commonly used in recruitment maneuvers for healthy patients. Box plots show the first and third quartiles, with the center line denoting the median and whiskers showing the minimum and maximum.

ventilation strategies used. The pneumothorax pressures that we describe greatly surpass the recommended recruitment PIPs in the literature, even in severely sick lungs. According to our results, a PIP of $90.5 \pm 15.7 \mathrm{~cm} \mathrm{H}_{2} \mathrm{O}$ causes pneumothorax in healthy newborn piglets. Similar data were described in adult cadavers $\left(100-110 \mathrm{~cm} \mathrm{H}_{2} \mathrm{O}\right.$ pressure range) by Malhotra and Wright in 1961.24 These data are also compatible with the results from a newborn ex vivo open thorax model (50-70-cm $\mathrm{H}_{2} \mathrm{O}$ PIP range) done by García-Fernández et $\mathrm{al}^{22}$ in healthy rabbits. In the latter study, pneumothorax PIPs are slightly lower, probably due to the fact that it used an open thorax model without any chest wall protection; these authors have already suggested that pneumothorax pressures in patients with an intact chest wall should be higher, since a closed system reduces transpulmonary pressure by raising pleural pressure, although a child's chest wall is elastic, and the protection it supports is limited compared with adults, a hypothesis that our study supports. In the Malhotra and Wright study ${ }^{24}$ done with cadavers, barotrauma pressures rose up to the wide range of $180-260 \mathrm{~cm} \mathrm{H}_{2} \mathrm{O}$ if external chest wall compression was applied, thus reducing the transpulmonary pressure. Therefore, as described in the literature, transpulmonary pressure plays a key role in barotrauma development. 25,26

In our study, pneumothorax was observed mainly within the first 4-6 breaths rather than at the end of the 2-min pressure level. Just 1 of the 10 animals developed pneumothorax at the end of the pressure step. Therefore, PIP could be more relevant than the duration of pressure. Pneumothorax was found to be mainly an early dynamic event at excessive pressures; however, it remains possible that certain lungs may rupture when high pressures are maintained over a prolonged time. These results are consistent with the data obtained in the open thorax model discussed previously. ${ }^{22}$

Although our study was not originally designed to assess the hemodynamic implications of these high pressures producing pneumothorax, we found interesting data that need to be discussed because barotrauma and hemodynamic impairment are among the main concerns of clinicians during recruitment maneuvers. The zero PEEP group did have greater hemodynamic impact than the PEEP ventilatory strategy. Hypotension is significantly greater in the zero PEEP group, with a $20 \%$ decrease from baseline in mean arterial pressure, systolic arterial pressure, and diastolic arterial pressure at the PIP range of $35-40 \mathrm{~cm} \mathrm{H}_{2} \mathrm{O}$, whereas in the PEEP group, pressures associated with hypotension start at $\mathrm{PIP}=60 \mathrm{~cm} \mathrm{H}_{2} \mathrm{O} / \mathrm{PEEP}=45 \mathrm{~cm} \mathrm{H}_{2} \mathrm{O}$. Therefore, it was safe for the PEEP group to reach pressures up to $50 \mathrm{~cm} \mathrm{H}_{2} \mathrm{O}$, both in terms of risk for pneumothorax development and hemodynamic repercussions, stressing the relevance of limiting driving-pressures when performing recruitment maneuvers, probably at inspiratory driving pressures $<15 \mathrm{~cm} \mathrm{H}_{2} \mathrm{O}$ as recently described for adults. ${ }^{27}$ Pulse showed the highest endurance to high pressures: the zero PEEP group presented bradycardia significantly earlier, at PIPs of $40 \mathrm{~cm} \mathrm{H}_{2} \mathrm{O}$, whereas the PEEP group showed bradycardia at PIP $=70 \mathrm{~cm} \mathrm{H}_{2} \mathrm{O} / \mathrm{PEEP}=$ $50 \mathrm{~cm} \mathrm{H}_{2} \mathrm{O}$. Bradicardia in the pediatric population is a well-known side effect of the sustained 40-cm $\mathrm{H}_{2} \mathrm{O}$ CPAP recruitment maneuver, whose use is now strongly discouraged. ${ }^{23}$

One of the more significant findings of the study is that hemodynamic compromise occurred in the zero PEEP group at considerably lower PIPs than those that caused pneumothorax. This important but unexpected finding, that a larger $\delta$-pressure seems to induce more hemodynamic compromise with the same PIP, suggests that perhaps venous return is more compromised in this condition. Therefore, we find that hypotension and bradycardia, when an inspiratory driving pressure $<15 \mathrm{~cm} \mathrm{H}_{2} \mathrm{O}$ is not preserved, are important side effects of PIP that actually occurred sooner than barotrauma in our experiment and, what is more important, at a common range of pressures in the 
clinical setting. Moreover, all animals suffered asystole before pneumothorax during our experiments. This fact stresses the relevance of the hemodynamic impact of high PIPs in the neonatal population and should raise concern about the hemodynamic impact and risk of death at pressures somewhat lower than those causing pneumothorax.

Regarding the mean arterial pressure highest values, in the PEEP group, these were achieved $>35 \mathrm{~cm} \mathrm{H}_{2} \mathrm{O}$, the usual PIP goal during recruitment maneuvers, whereas the zero PEEP strategy reached maximum values at the level of $20 \mathrm{~cm} \mathrm{H} \mathrm{H}_{2} \mathrm{O}$ and thereafter started hypotension. These findings add to the relevance that a fixed inspiratory driving pressure $<15 \mathrm{~cm} \mathrm{H}_{2} \mathrm{O}$ may have in the hemodynamics of recruitment maneuvers. ${ }^{27}$ Animals in the PEEP group slowly turned more tachycardic during the experiment, reaching the highest pulse values with PIPs of $45 \mathrm{~cm} \mathrm{H}_{2} \mathrm{O} / \mathrm{PEEP}$ of $30 \mathrm{~cm} \mathrm{H}_{2} \mathrm{O}$. This phenomenon could be due to a positive sympathetic stimulation with the increasing high pressures. ${ }^{28}$

The main limitation of our study may be the fact that it was done in healthy lungs, with no lung injury group with which to compare the results. Our idea was primarily to determine the pressures producing pneumothorax in healthy lungs, since this side effect may deter clinicians from performing recruitment maneuvers in the usual clinical setting of the operating theater. We found interesting data regarding hypotension and bradycardia that should be compared as well with lung-injured patients. Healthy lungs could, however, present earlier hemodynamic impairment than sick lungs due to their greater elasticity and the more efficient pressure transmission to the lung capillaries, thus being more likely to collapse.

There are, however, other limitations to our study: We did not perform computed tomography scanning to determine whether subtle lung damage was produced before pleural leaks were witnessed; nor did we check for other signs of barotrauma, such as pneumomediastinum. We did not make histological assessment of the lung afterward; nevertheless, there are studies available that have focused on high-pressure histologic lung lesions. ${ }^{29}$ Hemodynamic impact was a secondary goal, and the study was not designed for that purpose. Therefore, we did not measure cardiac output; nor was the preload status of our animals thoroughly assessed. A larger sample size could have shown significance in some values as mentioned previously.

\section{Conclusions}

This study is the first one to our knowledge measuring pneumothorax pressures in an in vivo model, either adult or pediatric, and shows similar data as those done ex vivo. According to our results, the recruitment maneuver pressures used in the clinical setting of the operating theater are considerably lower than those PIPs producing pneumothorax in our in vivo healthy newborn model.

We found unexpected results regarding hemodynamics: Animals in both groups had hemodynamic impact, but there are data pointing toward better hemodynamic performance to high ventilatory pressures when limiting inspiratory driving pressure, probably $<15 \mathrm{~cm} \mathrm{H}_{2} \mathrm{O}$; a large $\delta$-pressure seems to induce more hemodynamic compromise with the same PIP, and all animals suffered asystole and subsequently died before presenting pneumothorax. More studies should be performed specifically to assess the hemodynamic impact and barotrauma pressures in severely injured lungs.

\section{ACKNOWLEDGMENTS}

We thank Dr Carlota Largo Aramburu and Dr Agustín Mendiola for assistance with the animal preparation and cannulation and Dr Madero for the statistical analysis.

\section{REFERENCES}

1. Bendixen HH, Hedley-Whyte J, Laver MB. Impaired oxygenation in surgical patients during general anesthesia with controlled ventilation. A concept of atelectasis. N Engl J Med 1963;269:991-996.

2. Hedenstierna G, Edmark L. Mechanisms of atelectasis in the perioperative period. Best Pract Res Clin Anaesthesiol 2010;24(2):157-169.

3. Rothen HU, Neumann P, Berglund JE, Valtysson J, Magnusson A, Hedenstierna G. Dynamics of re-expansion of atelectasis during general anaesthesia. Br J Anaesth 1999;82(4):551-556.

4. Tusman G, Böhm S. Prevention and reversal of lung collapse during the intra-operative period. Best Pract Res Clin Anaesthesiol 2010; 24(2):183-197.

5. Tusman G, Böhm S, Tempra A, Melkun F, García E, Turchetto E, et al. Effects of recruitment maneuver on atelectasis in anesthetized children. Anesthesiology 2003;98(1):14-22.

6. Severgnini P, Selmo G, Lanza C, Chiesa A, Frigerio A, Bacuzzi A, Dionigi G, Novario R, Gregoretti C, de Abreu MG, Schultz MJ, Jaber S, Futier E, Chiaranda M, Pelosi P. Protective mechanical ventilation during general anesthesia for open abdominal surgery improves postoperative pulmonary function. Anesthesiology 2013; 118(6):1307-1321.

7. Tusman G, Böhm SH, Sipmann FS, Maisch S. Lung recruitment improves the efficiency of ventilation and gas exchange during onelung ventilation anaesthesia. Anesth Analg 2004;98(6):1604-1609, table of contents.

8. Barbas CS, de Matos GF, Okamoto V, Borges JB, Amato MB, de Carvalho CR. Lung recruitment maneuvers in acute respiratory distress syndrome. Respir Care Clin N Am 2003;9(4):401-418, vii.

9. Barbas CS, de Matos GF, Pincelli MP, da Rosa Borges E, Antunes $\mathrm{T}$, de Barros JM, et al. Mechanical ventilation in acute respiratory failure: recruitment and high positive end-expiratory pressure are necessary. Curr Opin Crit Care 2005;11(1):18-28.

10. Farias L, Faffe D, Xisto D, Santana M, Lassance R, Prota L, et al. Positive end-expiratory pressure prevents lung mechanical stress caused by recruitment/derecruitment. J Appl Physiol 2005;98(1):53-61.

11. Oba Y, Thameem D, Zaza T. High levels of PEEP may improve survival in acute respiratory distress syndrome: a meta-analysis. Respir Med 2009;103(8):1174-1181.

12. Odenstedt $\mathrm{H}$, Lindgren $\mathrm{S}$, Olegård $\mathrm{C}$, Erlandsson $\mathrm{K}$, Lethvall S, Aneman A, Stenqvist O, Lundin S. Slow moderate pressure recruitment maneuver minimizes negative circulatory and lung mechanic 


\section{Neonatal Pneumothorax Pressures in Lung Recruitment Maneuvers}

side effects: evaluation of recruitment maneuvers using electric impedance tomography. Intensive Care Med 2005;31(12):1706-1714.

13. Hansen LK, Koefoed-Nielsen J, Nielsen J, Larsson A. Are selective lung recruitment maneuvers hemodynamically safe in severe hypovolemia? An experimental study in hypovolemic pigs with lobar collapse. Anesth Analg 2007;105(3):729-734.

14. Boussarsar M, Thierry G, Jaber S, Roudot-Thoraval F, Lemaire F, Brochard L. Relationship between ventilatory settings and barotrauma in the acute respiratory distress syndrome. Intensive Care Med 2002; 28(4):406-413.

15. Meade MO, Cook DJ, Griffith LE, Hand LE, Lapinsky SE, Stewart TE, et al. A study of the physiologic responses to a lung recruitment maneuver in acute lung injury and acute respiratory distress syndrome. Respir Care 2008;53(11):1441-1449.

16. Rzezinski AF, Oliveira GP, Santiago VR, Santos RS, Ornellas DS, Morales MM, et al. Prolonged recruitment manouvres improves lung function with less ultrastructural damage in experimental mild acute lung injury. Respir Physiol Neurobiol 2009;169(3):271-281.

17. Steimback PW, Oliveira GP, Rzezinski AF, Silva PL, Garcia CS, Rangel G, et al. Effects of frequency and inspiratory plateau pressure during recruitment manoeuvres on lung and distal organs in acute lung injury. Intensive Care Med 2009;35(6):1120-1128.

18. Halbertsma FJ, van der Hoeven JG. Lung recruitment during mechanical positive pressure ventilation in the PICU: what can be learned from the literature? Anaesthesia 2005;60(8):779-790.

19. Mehta NM, Arnold JH. Mechanical ventilation in children with acute respiratory failure. Curr Opin Crit Care 2004;10(1):7-12.

20. Pavone LA, Albert S, Carney D, Gatto LA, Halter JM, Nieman GF. Injurious mechanical ventilation in the normal lung causes a progressive pathologic change in dynamic alveolar mechanics. Crit Care 2007;11(3):R64.
21. Harris T. Physiological principles. In: Goldsmith JP, Karotkined EH, editors. Assisted ventilation of the neonate. Philadelphia: WB Saunders; 1988:P22-P69.

22. García-Fernández J, Canfrán S, de Segura Álvarez-Gómez I, SuárezSipmann F, Aguado D, Hedenstierna G. Pressure safety range of barotrauma with lung recruitment manoeuvres: a randomised experimental study in a healthy animal model. Eur J Anaesthesiol 2013; 30(9):567-574.

23. Celebi S, Köner O, Menda F, Korkut K, Suzer K, Cakar N. The pulmonary and hemodynamic effects of two different recruitment maneuvers after cardiac surgery. Anesth Analg 2007;104(2):384390.

24. Malhotra MS, Wright HC. The effects of a raised intrapulmonary pressure on the lungs of fresh unchilled cadavers. J Pathol Bacteriol 1961;82:198-202.

25. Hernandez LA, Peevy KJ, Moise AA, Parker JC. Chest wall restriction limits high airway pressure-induced lung injury in young rabbits. J Appl Physiol 1989;66(5):2364-2368.

26. Suarez-Sipmann F, Böhm SH, Tusman G, Pesch T, Thamm O, Reissmann $\mathrm{H}$, et al. Use of dynamic compliance for open lung positive end-expiratory pressure titration in an experimental study. Crit Care Med 2007;35(1):214-221.

27. Amato M, Meade MO, Slutsky AS, Brochard L, Costa EL, Schoenfeld DA, et al. Driving pressure and survival in the acute respiratory distress syndrome. N Engl J Med 2015;372(8):747-755.

28. Luce JM. The cardiovascular effects of mechanical ventilation and positive end-expiratory pressure. JAMA 1984;252(6):807-811.

29. Webb HH, Tierney DF. Experimental pulmonary edema due to intermittent positive pressure ventilation with high inflation pressures: protection by positive end-expiratory pressure. Am Rev Respir Dis 1974;110(5):556-565.

This article is approved for Continuing Respiratory Care Education credit. For information and to obtain your CRCE

(free to AARC members) visit

www.rcjournal.com

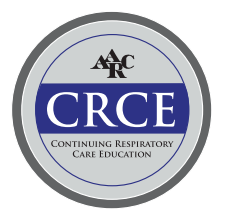

